\title{
Emotional reactivity, coping style and cancer trauma symptoms
}

\author{
Włodzimierz Oniszczenko, Agnieszka Laskowska
}

Faculty of Psychology, University of Warsaw, Poland

Submitted: 7 December 2010

Accepted: 31 January 2011

Arch Med Sci 2014; 10, 1: 110-116

DOI: 10.5114/aoms.2013.33069

Copyright @ 2014 Termedia \& Banach

\section{Abstract}

Introduction: This article studies the relationship between emotional reactivity and coping style on the one hand and intensity of symptoms of trauma in adult patients with cancer on the other hand.

Material and methods: The study was conducted on 150 patients, 55 women and 95 men, hospitalized for diagnosed cancer. Temperament was assessed with the Formal Characteristics of Behaviour - Temperament Inventory (FCB-TI). Coping style was assessed with the Polish version of the Mental Adjustment to Cancer Scale (Mini-MAC). Intensity of intrusion/hyperarousal and avoidance/numbing was assessed with the Factorial Version Inventory (PTSD), a quantitative measure of trauma-related symptoms.

Results: The outcomes of this study suggest that individual coping style is what determines the intensity of trauma-related symptoms most strongly. Destructive coping style accounts for $49 \%$ of the variance of symptom intensity and emotional reactivity accounts for $6 \%$. Combined, destructive coping style and emotional reactivity account for $55 \%$ of the variance of general post-traumatic stress symptoms.

Conclusions: Destructive coping style (more important determinant of trauma symptoms) and high emotional reactivity as one of temperament traits are conducive to intensification of cancer trauma symptoms in adult patients. Our findings suggest that constructive coping style and low emotional reactivity may act as a specific protector against cancer trauma symptoms in adults.

Key words: cancer, coping style, temperament, adult.

\section{Introduction}

The purpose of the present study was to determine the relationship between emotional reactivity as a personality (temperament) trait and cancer trauma symptoms in adults. We had not previously tested the hypothetical role of emotional reactivity in the development of cancer trauma. We view this trait, like other personality traits, as a risk factor for occurrence and intensity of trauma-related symptoms. We also think that coping styles and strategies adopted post-traumatically are important modifiers of experienced trauma-related symptoms. They are an important component of the process of psychological adjustment to illness and they help to control trauma-related symptoms. Different coping styles vary in effectiveness and may therefore either enhance or reduce the consequences of trauma. These two variables, emotional reactivity and coping style in a real-life situation, may modify the intensity of trauma, acting as either protective or aggravating factors.

\author{
Corresponding author: \\ Prof. Włodzimierz Oniszczenko \\ Faculty of Psychology \\ University of Warsaw \\ 5-7 Stawki St \\ 00-183 Warsaw, Poland \\ Phone: +48 225549705 \\ Fax: +48226357991 \\ E-mail:wlodek@psych.uw.edu.pl
}


In this study we focused on two major symptoms of trauma, intrusion/hyperarousal $(\mathrm{I} / \mathrm{H})$ and avoidance/numbing $(\mathrm{A} / \mathrm{N})$. We identified these symptoms by factor analysing symptoms accompanying dramatic experiences. The two dimensions were constructed on the basis of the symptoms of post-traumatic stress listed in DSM-IV [1]. Intrusion/hyperarousal involves recurrent thoughts relating to the traumatic event and causing arousal. Avoidance/numbing involves avoidance of traumarelated stimuli and subdued response to these stimuli [2]. Presence of intrusive and avoidant symptoms in cancer patients has been demonstrated elsewhere [3].

Earlier research has shown that various psychological factors play a significant role in the aetiology of trauma-related symptoms. Ozer et al. [4] conducted a large meta-analysis and found that peri-traumatic psychological processes are the best predictors of stress caused by trauma other than disease. These processes include emotional reactions (fear, anger, helplessness) and dissociative experiences during or directly following trauma. Kangas et al. [5] found that dissociative experiences contribute significantly to the development of posttraumatic stress disorder (PTSD) in patients with cancer. Other predictors of PTSD in this group of patients include health status, depressive personality, earlier traumatic experiences, age and other demographic variables [6], diagnosed stage of cancer [7], subjective appraisal of threat [8] and presence of acute stress syndrome in the initial phase of trauma [9].

Some researchers suggest that personality traits can play a significant role in response to trauma $[10,11]$. Neuroticism is one of the personality traits associated with trauma-related symptoms. The relationship between neuroticism and post-traumatic stress has been demonstrated in the general population [12, 13], several patient groups [14-17], as well as in Holocaust victims, i.e. people submitted to a very specific form of prolonged trauma [18].

The regulative theory of temperament (RTT) [19] highlights the importance of personality, and temperament in particular, for human behaviour under stress. The temperament traits postulated by RTT are expressed in all human behaviours and all situations in which people function, especially in situations which are extremely arousing. These traits are so important because temperament is present from birth and because the related biological mechanisms participate in the regulation of the individual level of activation. Emotional reactivity is particularly important because it is related to such temperament traits as harm avoidance, neuroticism and anxiety. The increased significance of these traits in traumatic situations has been demonstrated elsewhere [20-22].
The concept of emotional reactivity (ER) as presented in RTT assumes that ER is the tendency to react intensely to emotogenic stimuli and is manifest in high sensitivity and low emotional resistance. Emotional reactivity is rooted in individual differences in arousal. This temperament trait exists prior to the stressors which lead to trauma and can be viewed as a factor responsible for susceptibility to post-traumatic stress disorder. Emotional reactivity can also strengthen the effects of trauma, just like other related traits such as neuroticism, extraversion/introversion, anxiety or harm avoidance [19, 23]. So far, the relationship between emotional reactivity and trauma-related symptoms has been demonstrated for flood trauma [24] and the trauma experienced by firemen when rescuing the victims of road traffic accidents [25]. In both these studies a positive relationship was found between ER and intensity of trauma-related symptoms. The other temperament traits postulated by RTT are: briskness (the tendency to react swiftly, to maintain a high tempo of activity and to switch easily between one behaviour or response and another, appropriately to changes in the environment), perseveration (the tendency to continue and repeat behaviour upon discontinuation of the evoking stimuli or situations), sensory sensitivity (capacity to respond to sensory stimuli of low stimulating value), endurance (the capacity to respond adequately in situations demanding prolonged or highly stimulating activity and/or under intense external stimulation) and activity (the tendency to engage in highly stimulating behaviours or behaviours supplying stimulation from their external environment) [26].

Animal studies of RHA/Verh and RLA/Verh rats differing in emotional reactivity [27] lend support to the hypothetical importance of emotional reactivity for behaviour in stressful situations. The authors of these studies demonstrated that differences in animal behaviour, but also in c-Fos protein expression and bioelectric brain activity, were only found in anxiety-evoking situations. This confirms one of the postulates of RTT that the significance of temperament, including ER, is particularly manifest in highly stimulating situations (situations which evoke powerful emotions).

Many researchers have also pointed out the importance of coping styles for the development of the post-traumatic response in patients with cancer. Avoidant styles [28-30], sense of hopelessness [31] and emotion-focused coping [32] are the least effective coping styles and are conducive to the development of post-traumatic stress disorder. Fighting spirit and emotional expressiveness [33] are the most effective coping styles. On the other hand, a meta-analysis by Prati and Pietrantoni [34] showed that resorting to religion and positive reevaluation of the situation, a form of coping, have a positive effect on post-traumatic development. 
The research presented in this article focused on the importance of individual differences in temperament and coping style for the intensity of trauma-related symptoms in patients with a severe and life-threatening disease. In accordance with the regulative theory of temperament [19], we treated temperamental traits as moderators of intensity of trauma-related symptoms. Considering the potentia significance of emotional reactivity and coping style, we predicted that both these variables would have either a protective function or an aggravating function with respect to symptoms.

\section{Material and methods}

\section{Participants}

Adult men and women hospitalized at the Department of Oncology of the Military Medical Institute in Warsaw participated in the study. The study was conducted on 150 patients including 55 women, all with diagnosed breast cancer, and 95 men, all with various diagnosed cancers: 17 (18\%) had kidney carcinoma, 16 (17\%) had colorectal carcinoma, 14 (15\%) had pulmonary carcinoma, 11 (12\%) had testicle carcinoma, and 37 (38\%) had other malignant tumours. The mean age of participants was: women 48.3 years $(S D=10.68)$, men 50.2 years $(S D=15.5)$. The mean interval between final medical diagnosis and trauma-related symptom assessment (in months) was 3.3 (SD = 1.33) for women and 4.35 (SD = 1.14) for men. In the studied group 34 participants $(22.7 \%)$ had higher education, 78 participants (52\%) had secondary education and 38 participants (25.3\%) had primary education. No cognitive dysfunction that may have impeded psychological diagnosis was observed. Participation was voluntary and anonymous and participants were not remunerated. The research project was accepted by the local Research Ethics Committee at the Faculty of Psychology, University of Warsaw.

\section{Assessment}

Temperament traits were assessed with the Formal Characteristics of Behaviour - Temperament Inventory, FCB-TI [35]. This test measures six temperament traits: briskness, perseveration, sensory sensitivity, emotional reactivity, endurance and activity. It has 120 items, 20 items per scale (each scale can yield a total score of 0 to 20). Respondents respond Yes or No to each item. The FCB-TI has good psychometric parameters. Cronbach $\alpha$ vary from 0.72 to 0.86 depending on the scale, while test-retest coefficients vary from 0.69 (briskness) to 0.90 (activity).

Coping styles were assessed with the Polish version [36] of the Mental Adjustment to Cancer Scale (Mini-MAC) originally constructed by Watson, Lawa,
Dos Santos, Greer, Baruch and Bliss. This scale measures reactions to cancer diagnosis. The Polish version of the Mini-MAC has 28 diagnostic items. Each item is rated on a 4-point scale where 1 means "definitely disagree" and 4 means "definitely agree". The Mini-MAC measures two coping styles and four coping strategies. Each strategy can score from 7 to 28 and each coping scale, destructive or constructive, can score from 14 to 56 . The first coping style, called the constructive coping style in the Polish version of the Mini-MAC, includes two active coping strategies, fighting spirit, a strategy inducing the patient to view the disease as a personal challenge and to take action to combat it, and positive re-evaluation, a strategy inducing the patient to reorganize the disease problem so as to become more completely aware of its seriousness and find hope and satisfaction in years already lived. The second coping style, called the destructive coping style in the Polish version of the Mini-MAC, involves succumbing to the difficult situation, helplessness with respect to the tumour and focus on emotions relating to the disease situation. This style includes two coping strategies, helplessness/hopelessness, i.e. feelings of powerlessness, confusion and passive succumbing to illness, and anxious preoccupation, i.e. disease-related anxiety, mainly perceived as an anxiety-invoking and uncontrollable threat causing every change to be interpreted as a signal of health status deterioration. Cronbach $\alpha$ for the Polish version range from 0.70 to 0.92 .

Cancer trauma symptoms were assessed with the PTSDF, a questionnaire measuring intrusion/hy perarousal $(I / H)$ (recurrent thoughts relating to the traumatic event and causing arousal) and avoidance/numbing $(A / N)$ (avoidance of trauma-related stimuli and weakened response to these stimuli). This questionnaire also has a General Scale, a generalized measure of intensity of all the measured symptoms [2]. The PTSDF has 30 items. Each item is rated on a 4-point scale from 1 (symptom is absent) to 4 (symptom is always present). For the purpose of analyses, test scores are transformed to a 0-3 point scale and so the general PTSDF score can range from 0 to 90 and the scores for each sub-scale, $\mathrm{I} / \mathrm{H}$ and $\mathrm{A} / \mathrm{N}$, can vary from 0 to 45 . The PTSDF has high reliability (Cronbach $\alpha$ from 0.90 to 0.97 ).

\section{Statistical analysis}

The statistical analysis was conducted by means of the Statistical Package for the Social Sciences (SPSS), version 14.0. Relations between the variables were tested using the Pearson product-moment and Spearman correlation coefficients. Validity of predictions of trauma-related symptom intensity on the basis of temperament traits and coping style was estimated using hierarchical regression analysis. 
Table I. Descriptive characteristics of temperament traits, cancer trauma symptoms scales (PTSDF) and coping styles in the studied group

\begin{tabular}{|c|c|c|c|c|c|c|c|c|}
\hline \multirow[t]{2}{*}{ Variables } & \multicolumn{2}{|c|}{ Total $(n=150)$} & \multicolumn{2}{|c|}{ Women $(n=55)$} & \multicolumn{2}{|c|}{ Men $(n=95)$} & \multirow{2}{*}{$\begin{array}{c}\text { Women/men } \\
\text { difference } \\
\text { test } t(148)\end{array}$} & \multirow{2}{*}{$\begin{array}{c}\text { Cohen's } \\
d\end{array}$} \\
\hline & Mean & SD & Mean & SD & Mean & SD & & \\
\hline \multicolumn{9}{|l|}{ Temperament traits } \\
\hline Briskness & 13.91 & 4.35 & 14.28 & 4.46 & 13.70 & 4.31 & $-0.89^{(a)}$ & 0.13 \\
\hline Perseveration & 12.33 & 4.00 & 14.00 & 3.39 & 11.39 & 4.03 & $-4.03^{\star \star \star}$ & 0.70 \\
\hline Sensory sensitivity & 9.15 & 2.04 & 9.69 & 1.87 & 8.85 & 2.08 & -2.43 & 0.42 \\
\hline Emotional reactivity & 10.42 & 4.79 & 11.93 & 4.22 & 9.57 & 4.90 & $-2.96^{\star *}$ & 0.52 \\
\hline Endurance & 9.93 & 1.72 & 9.98 & 1.60 & 9.90 & 1.80 & $-0.22^{\mathrm{a}}$ & 0.05 \\
\hline Activity & 8.06 & 4.82 & 6.13 & 4.54 & 9.15 & 4.66 & $3.84^{* * *}$ & -0.66 \\
\hline PTSDF General Scale & 34.18 & 17.47 & 39.83 & 16.27 & 31.00 & 17.41 & $-3.05^{\star \star}$ & 0.52 \\
\hline Intrusion/arousal & 19.15 & 10.04 & 23.63 & 8.70 & 16.64 & 9.92 & $-4.33^{\star \star *}$ & 0.75 \\
\hline Avoidance/numbing & 15.03 & 9.01 & 16.20 & 9.34 & 14.36 & 8.81 & 1.20 & 0.20 \\
\hline Destructive style & 31.04 & 8.68 & 33.57 & 8.08 & 29.61 & 8.73 & $-2.74^{\star *}$ & 0.47 \\
\hline Anxious preoccupation & 17.57 & 4.94 & 19.43 & 4.56 & 16.53 & 4.86 & $-3.58^{\star * \star}$ & 0.62 \\
\hline Helplessness-hopelessness & 13.47 & 4.59 & 14.15 & 4.70 & 13.08 & 4.51 & $-1.07^{a}$ & 0.23 \\
\hline Constructive style & 44.02 & 6.46 & 42.00 & 5.87 & 45.15 & 6.53 & $2.94^{\star \star}$ & -0.51 \\
\hline Positive re-evaluation & 21.40 & 3.66 & 20.44 & 3.63 & 21.94 & 3.59 & $-2.25^{a, \star}$ & -0.42 \\
\hline Fighting spirit & 22.62 & 3.60 & 21.56 & 3.22 & 23.22 & 3.68 & $2.78^{\star *}$ & -0.48 \\
\hline
\end{tabular}

${ }^{a} Z$ value for Mann-Whitney $U$ test; ${ }^{*} p<0.05,{ }^{* *} p<0.01,{ }^{* * *} p<0.001$

\section{Results}

Table I shows the means and standard deviations for temperament traits, trauma-related symp-

Table Il. Correlation coefficients (Pearson's $r$ ) between temperament traits, coping styles and intensity of cancer trauma symptoms in the studied group $(n=150)$

\begin{tabular}{|c|c|c|c|}
\hline Variables & I/A & $\mathrm{A} / \mathrm{N}$ & $\begin{array}{c}\text { General } \\
\text { Scale }\end{array}$ \\
\hline \multicolumn{4}{|l|}{ Temperament } \\
\hline Briskness & $-0.35^{a, \star *}$ & $-0.38^{\mathrm{a}, \star *}$ & $-0.38^{\mathrm{a}, \star \star *}$ \\
\hline Perseveration & $0.53^{\star *}$ & $0.24^{\star *}$ & $0.43^{\star \star}$ \\
\hline Sensory sensitivity & -0.00 & -0.05 & -0.03 \\
\hline Emotional reactivity & $0.54^{\star *}$ & $0.42^{* *}$ & $0.53^{\star *}$ \\
\hline Endurance & $-0.19^{a, *}$ & $-0.17^{\mathrm{a}, *}$ & $-0.20^{a, *}$ \\
\hline Activity & $-0.21^{\star *}$ & $-0.23^{\star *}$ & $-0.24^{\star \star}$ \\
\hline \multicolumn{4}{|l|}{ Coping styles } \\
\hline Destructive style & $0.67^{* *}$ & $0.62^{* *}$ & $0.70^{\star *}$ \\
\hline Anxious preoccupation & $0.64^{* \star}$ & $0.43^{\star *}$ & $0.59^{\star *}$ \\
\hline Helplessness-hopelessness & $0.57^{\mathrm{a}, * \star}$ & $0.72^{\mathrm{a}, * *}$ & $0.70^{a, * *}$ \\
\hline Constructive style & -0.08 & $-0.30^{\star \star}$ & $-0.20^{*}$ \\
\hline Positive re-evaluation & $0.01^{a}$ & $-0.18^{a, \star}$ & $-0.10^{\mathrm{a}}$ \\
\hline Fighting spirit & $-0.18^{*}$ & $-0.35^{\star *}$ & $-0.29^{\star *}$ \\
\hline
\end{tabular}

a Spearman's correlation coefficient; I/A - intrusion/arousal, A/N - avoidance/numbing; ${ }^{* *} p<0.01,{ }^{*} p<0.05$ tom intensity and coping styles and strategies for the whole sample and separately for women and men. The two groups were compared using the $t$ test and the Mann-Whitney $U$ test when the assumption that variables are normally distributed was not met. Compared with men, women were more perseverating and emotionally reactive. They had higher general trauma-related symptom intensity, especially on the anxious preoccupation scale. Men were more active and had more constructive coping styles (i.e. had higher scores than women on both sub-dimensions of this style).

Table II presents the correlations between temperament traits and coping styles on the one hand and intensity of trauma-related symptoms (intrusion/hyperarousal and avoidance/numbing) on the other hand. A large correlation was found for emotional reactivity and trauma symptoms - general score. Moderate-to-large correlations were found for perseveration and general score (positive) and for briskness and general score (negative). Smallto-moderate correlations were found for endurance and activity on the one hand and PTSDF general score on the other hand. As far as coping style is concerned, a large correlation emerged for destructive coping style and its two sub-dimensions on the one hand and PTSDF general score on the other hand. Correlations for constructive style and its subdimension, fighting spirit, and PTSDF general score were small-to-moderate and they were all negative. 
Table III. The results of hierarchical regression analysis with destructive style, emotional reactivity, and gender as predictors of cancer trauma symptoms

\begin{tabular}{|c|c|c|c|c|c|c|}
\hline Model & $\mathrm{F}$ & $\mathrm{F} \Delta \mathrm{R}^{2}$ & $\mathrm{R}$ & $\mathrm{R}^{2}$ & Predictor & Semi-partial correlation \\
\hline Destructive style & $144.58^{\mathrm{a}, * * *}$ & - & 0.70 & 0.49 & Destructive style & $0.70^{\star * \star}$ \\
\hline \multirow[t]{2}{*}{$+\mathrm{ER}$} & \multirow[t]{2}{*}{$90.47^{\mathrm{b}, \star \star \star}$} & \multirow[t]{2}{*}{$18.89^{* \star *}$} & \multirow[t]{2}{*}{0.74} & \multirow[t]{2}{*}{0.55} & Destructive style & $0.53^{* * *}$ \\
\hline & & & & & Emotional reactivity & $0.24^{* * *}$ \\
\hline \multirow[t]{3}{*}{ + Gender } & \multirow[t]{3}{*}{$60.61^{c, * * *}$} & \multirow[t]{3}{*}{0.94} & \multirow[t]{3}{*}{0.75} & \multirow[t]{3}{*}{0.55} & Destructive style & $0.51^{\star \star *}$ \\
\hline & & & & & Emotional reactivity & $0.23^{* * *}$ \\
\hline & & & & & Gender & 0.06 \\
\hline
\end{tabular}

$E R$ - emotional reactivity; ${ }^{a} d f=1.148,{ }^{b} d f=2.147,{ }^{c} d f=3.146,{ }^{* * *} p<0.001$

Table III presents the results of the hierarchical regression analysis. The largest portion of variance of the PTSDF general score was accounted for by destructive coping style (49\%) and emotional reactivity increased explained variance by a further $6 \%$. Together, destructive coping style and emotional variance accounted for $55 \%$ of the variance of PTSDF general score. The results showed that gender is not an important variable.

\section{Discussion}

Our findings suggest that individual differences in coping style and emotional reactivity are important protective or risk factors for the intensity of cancer trauma symptoms. Above all, we demonstrated (see Table I) that, as far as temperament characteristics are concerned, women with cancer are more emotionally reactive than men. They are also more prone to prolonged reaction (more perseverating) and less active (seek less stimulation in accordance with the definition of this trait). Compared with men, women with cancer used a more destructive coping style, particularly anxious preoccupation. Men with cancer engaged in a constructive coping style in both its dimensions. When we compare trauma-related symptoms we see that women have higher general scores than men and are particularly more prone than men to intrusion/hyperarousal but not more to avoidance/numbing. These results suggest that high engagement in destructive coping style and high emotional reactivity are associated with high cancer trauma symptoms.

When we look at the correlations between the variables (Table II) we see that the temperament trait which correlates most positively with intensity of cancer trauma symptoms (intrusion/hyperarousal and avoidance/numbing and also the General Score) is emotional reactivity. A positive albeit slightly lower correlation was found for perseveration and cancer trauma symptoms. Briskness, activity and endurance correlated negatively with cancer trauma symptoms. One trait which did not correlate in any way with cancer trauma symptoms was sensory sensitivity. As far as coping style is con- cerned, the largest (positive) correlation with intensity of cancer trauma symptoms emerged for destructive coping style. Destructive coping style correlated most strongly (and positively) with two temperament traits, emotional reactivity $(0.44)$ and perseveration (0.43). If we look at the correlations between temperament traits and coping styles on the one hand and intensity of cancer trauma symptoms on the other hand, we find that patients with a susceptibility to intense emotional reactions (high emotional reactivity) and prolonged emotional reaction (high perseveration) and patients whose typical coping style is destructive manifest the highest intensity of cancer trauma symptoms. This pattern is exemplified by women in our study. Women had higher general cancer trauma symptoms than men and were also more reactive, more perseverating and engaged in a destructive coping style.

This result is consistent with our previous findings for firemen who developed post-traumatic stress symptoms following the trauma of participation in fire-fighting and rescuing road traffic accident victims [25]. Firemen who had high emotional reactivity and used an emotion-focused coping strategy had higher levels of PTSD symptoms. These data confirm that gender is probably not an important variable for the development of symptoms of trauma, which is consistent with the results of the hierarchical regression analysis (Table III).

The great significance of emotional reactivity as a risk factor for development of trauma has already been demonstrated in studies of flood victims and mining accident victims whatever the interval between the traumatic event and the assessment of trauma symptoms [24].

Our hierarchical regression analysis (Table III) with general level of intensity of trauma symptoms as the dependent variable showed that coping style accounted for the largest portion of the variance of trauma symptoms (49\%). Emotional reactivity accounted for $6 \%$ of the variance. "Gender" did not contribute significantly to the explanation of the variance of trauma symptoms.

Destructive coping style was a very powerful predictor of development of cancer trauma symptoms. 
Anxiety, passivity and helplessness in the face of illness presumably intensify the experience of stress. If we look at the correlation between emotional reactivity and destructive coping style we see that in patients who typically resort to a destructive coping style both of these variables account for a considerable portion of the intensity of cancer trauma symptoms (55\%) and are therefore good predictors. It is possible that emotional reactivity, which we viewed as a moderator of reaction to trauma, is conducive to the development of coping strategies which intensify the symptoms of trauma.

Our findings suggest that low emotional reactivity and a constructive coping style may act as a specific protector against cancer trauma symptoms. High emotional reactivity and a destructive coping style may act as a specific risk factor for cancer trauma symptoms.

Of course our study has its limitations. Above all our study sample was composed of people suffering from various forms of cancer. All the women had breast cancer, while the men were suffering from various types of cancer. This may result in different levels of stress and its symptoms, as people can be in varying degrees concerned about a type of cancer occurring to them, and forecasts as to its treatment. Also, it is not clear to what extent psychometrically assessed emotional reactivity changes (increases) due to the experience of illness. Also, we did not study the relationship between patients' functioning in conditions of illness or the treatment procedures they were undergoing and the intensity of cancer trauma symptoms. Nor did we check the effect of social support and its relation to the progression of illness or the accompanying stressful experiences. These are important factors known to affect the evaluation of sources of intensity of cancer trauma symptoms and should be looked at more closely in future research.

\section{Acknowledgments}

This study was funded by grant BST 1445/02-2009 from the Faculty of Psychology, University of Warsaw. We would like to thank Professor Cezary Szczylik, head of the Department of Oncology at the Military Medical Institute in Warsaw, and Dr Tomasz Sarosiek at the same department.

\section{References}

1. American Psychiatric Association (APA). Diagnostic and statistical manual of mental disorders (4th ed.). American Psychiatric Association: Washington, DC, 1994.

2. Strelau J, Zawadzki B, Oniszczenko W, Sobolewski A. The factorial version of the PTSD Inventory (PTSD-F): the development of a questionnaire aimed at assessing basic dimensions of posttraumatic stress disorder [Polish]. Przeglad Psychol 2002; 45: 149-76.
3. Kangas M, Henry JL, Bryant RA. Posttraumatic stress disorder following cancer. A conceptual and empirical review. Clin Psychol Rev 2002; 22: 499-524.

4. Ozer EJ, Best SR, Lipsey TL, Weiss DS. Predictors of posttraumatic stress disorder and symptoms in adults: a metaanalysis. Psychol Bull 2003; 129: 52-73.

5. Kangas M, Henry JL, Bryant RA. Predictors of posttraumatic stress disorder following cancer. Health Psychol 2005; 24: 579-85.

6. Smith MY, Redd WH, Peyser C, Vogl D. Post-traumatic stress disorder in cancer: a review. Psycho-Oncol 1999; 8: 521-37.

7. Boyer BA, Bubel D, Jacobs SR, et al. Posttraumatic stress in women with breast cancer and their daughters. Am J Fam Ther 2002; 30: 323-8.

8. Cordova MJ, Giese-Davis J, Golant M, Kronenwetter C, Chang V, Spiegel D. Breast cancer as trauma: posttraumatic stress and posttraumatic growth. J Clin Psychol Med Settings 2007; 14: 308-19.

9. Kangas M, Henry JL, Bryant RA. The relationship between acute stress disorder and posttraumatic stress disorder following cancer. J Consult Clin Psychol 2005; 73: 360-4.

10. Lauterbach D. Personality, trauma exposure, and posttraumatic stress disorder severity: moving beyond the monovariable predictor model. In: People under extreme stress. Strelau J, Klonowicz T (eds). Nova Science Publishers, New York 2006; 15-33.

11. McFarlane AC. The relationship between personality and posttraumatic stress disorder. In: People under extreme stress. Strelau J, Klonowicz T (eds). Nova Science Publishers, New York 2006; 1-14.

12. Cox BJ, MacPherson PSR, Enns MW, McWilliams LA. Neuroticism and self-criticism associated with posttraumatic stress disorder in a nationally representative sample. Behav Res Ther 2004; 42: 105-14.

13. Holeva V, Tarrier N. Personality and peritraumatic dissociation in the prediction of PTSD in victims of road traffic accidents. J Psychosom Res 2001; 51: 687-92.

14. Chung MC, Berger Z, Jones R, Rudd H. Posttraumatic stress disorder and general health problems following myocardial infarction (Post-MI PTSD) among older patients: the role of personality. Int J Geriatr Psych 2006; 21: 1163-74.

15. Engelhard IM, van den Hout MA, Schouten EGW. Neuroticism and low educational level predict the risk of posttraumatic stress disorder in women after miscarriage or stillbirth. Gen Hosp Psychiat 2006; 28: 414-7.

16. Kelly B, Raphael B, Judd F, et al. Posttraumatic stress disorder in response to HIV infection. Gen Hosp Psychiat 1998; 20: 345-52.

17. Otto MW, Perlman CA, Wernicke R, Reese HE, Bauer MS, Pollack MH. Posttraumatic stress disorder in patients with bipolar disorder: a review of prevalence, correlates, and treatment strategies. Bipolar Disord 2004; 6: 470-9.

18. Brodaty H, Joffe C, Luscombe G, Thompson C. Vulnerability to post-traumatic stress disorder and psychological morbidity in aged holocaust survivors. Int J Geriatr Psych 2004; 19: 968-79.

19. Strelau J. Temperament as a regulator of behavior. After fifty years of research. Eliot Werner Publications, Inc.: New York 2008

20. Yoon SJ, Jun CS, An H, Kang HR, Jun TY. Patterns of temperament and character in patients with posttraumatic stress disorder and their association with symptom severity. Compr Psychiatry 2009; 50: 226-31.

21. Borja SE, Callahan JL, Rambo PL. Understanding negative outcomes following traumatic exposure: the roles of neuroticism and social support. Psychol Trauma 2009; 1: 118-29. 
22. Zahradnik M, Stewart SH, Marshall GN, Schell TL, Jaycox LH. Anxiety sensitivity and aspects of alexithymia are independently and uniquely associated with posttraumatic distress. J Trauma Stress 2009; 22: 131-8.

23. Hornowska E. Temperamental determination of behaviour [Polish]. Bogucki Wydawnictwo Naukowe, Poznan 2003.

24. Strelau J, Zawadzki B. Trauma and temperament as predictors of intensity of posttraumatic stress disorder symptoms after disaster. Eur Psychol 2005; 10: 124-35.

25. Oniszczenko W, Szcześnik M. Temperament and coping styles as risk factors for posttraumatic stress [Polish]. Ann UMCS Med 2006; 60: 269-72.

26. Strelau J. The regulative theory of temperament: current status. Pers Indiv Differ 1996; 20: 131-42.

27. Meyza KZ, Boguszewski PM, Nikolaev E, Zagrodzka J. Diverse sensitivity of RHA/Verh and RLA/Verh rats to emotional and spatial aspects of a novel environment as a result of a distinct pattern of neuronal activation in the fear/anxiety circuit. Behav Genet 2009; 39: 48-61.

28. Jacobsen PB, Sadler IJ, Booth-Jones M., Soety E, Weitzner MA, Fields KK. Predictors of posttraumatic stress disorder symptomatology following bone marrow transplantation for cancer. J Consult Clin Psychol 2002; 70: 235-40.

29. Hampton MR, Frombach I. Women's experience of traumatic stress in cancer treatment. Health Care Women Int 2000; 21: 67-76.

30. Bruce M. A systematic and conceptual review of posttraumatic stress in childhood cancer survivors and their parents. Clin Psychol Rev 2006; 26: 233-56.

31. Gidron Y, Magen R, Ariad S. The relation between hopelessness and psychological and serological outcomes in Israeli women with breast-cancer. Psychol Health 2001; 16: 289-96.

32. Baschnagel JS, Gudmundsdottir B, Hawk Jr, LW, Beck JG. Post-trauma symptoms following indirect exposure to the September $11^{\text {th }}$ terrorist attacks: the predictive role of dispositional coping. J Anxiety Disord 2009; 23: 915-22.

33. Classen C, Koopman C, Angell K, Spiegel D. Coping styles associated with psychological adjustment to advanced breast cancer. Health Psychol 1996; 15: 434-7.

34. Prati G, Pietrantoni L. Optimism, social support, and coping strategies as factors contributing to posttraumatic growth: a meta-analysis. J Loss Trauma 2009; 14: 364-88.

35. Strelau J, Zawadzki B. The Formal Characteristics of Behavior - Temperament Inventory (FCB-TI): validity studies. Eur J Pers 1995; 9: 207-29.

36. Juczyński Z. Diagnostic tools in health promotion and psychology [Polish]. Pracownia Testow Psychologicznych PTP, Warszawa 2001. 